\title{
Drusen of the disc and retinal haemorrhages
}

\author{
J. D. BRODRIGK
}

Sheffield

Buried drusen of the optic discs are the main cause of difficulty in the diagnosis of early papilloedema. In a series of 28 cases of pseudopapilloedema, which had been mistakenly diagnosed as papilloedema due to brain tumour, Hoyt found buried drusen to be the major cause of confusion (Hoyt and Pont, 1962). Many of his patients had undergone unnecessary and often hazardous investigations, including arteriography, pneumoencephalography, ventriculography, and even burr holes.

The rare association between drusen of the optic disc and retinal haemorrhage has only recently received detailed mention eleswhere (Otradovec, and Vladyková ı970; Sanders, Gay, and Newman, 1971) apart from a few isolated reports as an incidental finding.

The presence of haemorrhages on or near the disc in association with buried drusen is of course liable to make clinical evaluation even more difficult. Having recently seen two cases of this nature, it was felt important to emphasize the association in the hope of facilitating the interpretation of the clinical signs, thus sparing patients the anxiety and potential hazards of unnecessary investigations.

The first report of drusen was a histological study by Müller ( 1858). This was followed ı years later by a description of the ophthalmoscopic appearances (Liebreich, I868). Since then many cases have been described and an extensive study with a comprehensive review of the literature was published by Lorentzen ( 1966 ).

Drusen consist of degenerative deposits of hyaline-like material composed of laminated homogeneous masses which frequently become calcified. They are invariably situated anterior to the lamina cribrosa where they can produce atrophy of the adjacent nerve fibres.

The clinical changes are localized to the disc, particularly the nasal aspect, which consequently appears swollen. The disc margins are irregular and blurred and the physiological cup is filled in. There is no hyperaemia and there are no exudates, but in I I per cent. of cases vascular anomalies in the form of arterial or venous loops may be found (Lorentzen, i 966 ).

Drusen are bilateral in 72 per cent. of cases, and can occur at any age and in either sex, with an incidence of 3.4 per thousand (Lorentzen, 1966). The normal clinical course is one of slow, progressive enlargement over many years. Central vision is almost never interfered with, but field defects can be found in 87 per cent of cases. The characteristic field defects are concentric constriction, baring of the blind spot, and nerve-fibre bundle defects (Lauber, I92 I; Rucker, I944; Lansche and Rucker, I957; Lorentzen, I966). Lorentzen described amblyopic attacks in 8 per cent. of his patients, a symptom that had been documented on eight previous occasions (Gifford, I895; Thompson, I898; Gibis, I 940; Chambers and Walsh, I95 I Lansche and Rucker, I957; McPherson, I955; Morax, I 963 ; Polliot and Lods, I963). 
Fluorescein angiography in papilloedema results in leakage of the dye, which diffuses into the surrounding retina. The disc margin is indistinct and the spread occurs mainly above and below in relation to the vessels. The most characteristic feature is the dilatation of the most superficial capillary net which manifests itself angiographically much more than normal (Fig. I $a, b$ ).

(a)

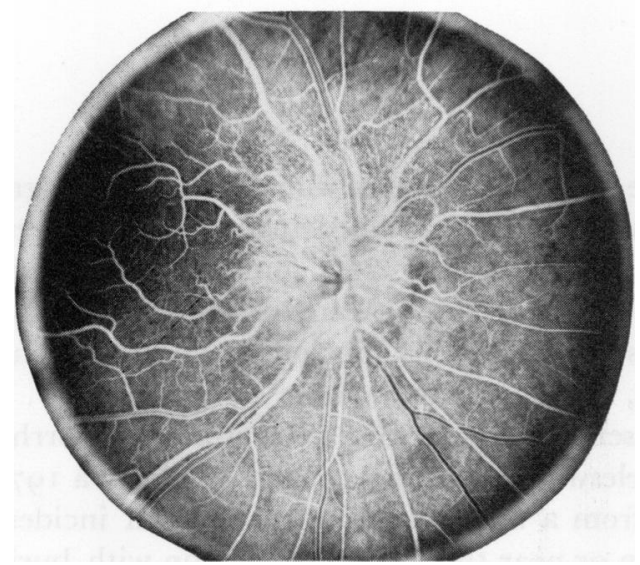

(b)

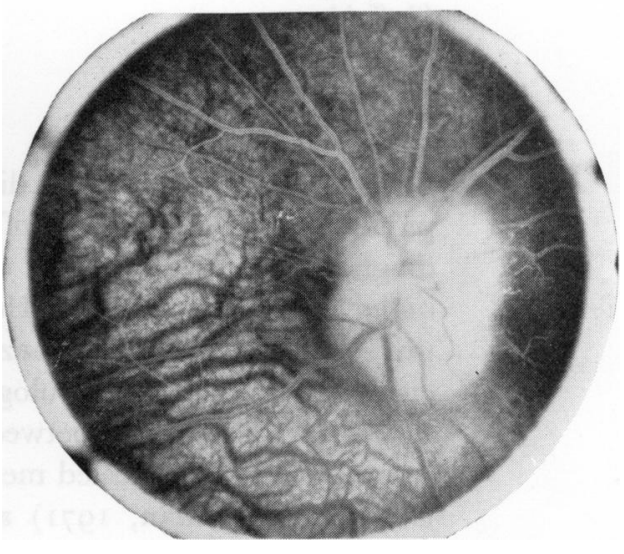

FIG. I (a) Papilloedema. Fluorescein angiogram, early venous phase, showing marked dilatation of the superficial capillary network

FIG. I (b) Papilloedema. Fluorescein angiogram, late phase, showing diffuse leakage of dye over the disc margins into the surrounding retina

In drusen of the disc there is irregular fluorescence. The disc margin is discrete and nodular and no leakage occurs along the vessels (Miller, Sanders, and ffytche, 1965; Ernest and Krill, I966; Sanders and ffytche, 1967; Rosen, 1969) (Fig. 2a, b).

(a)

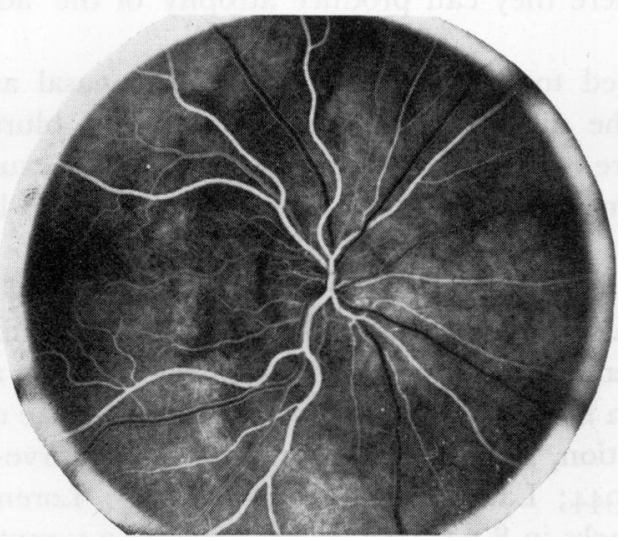

(b)

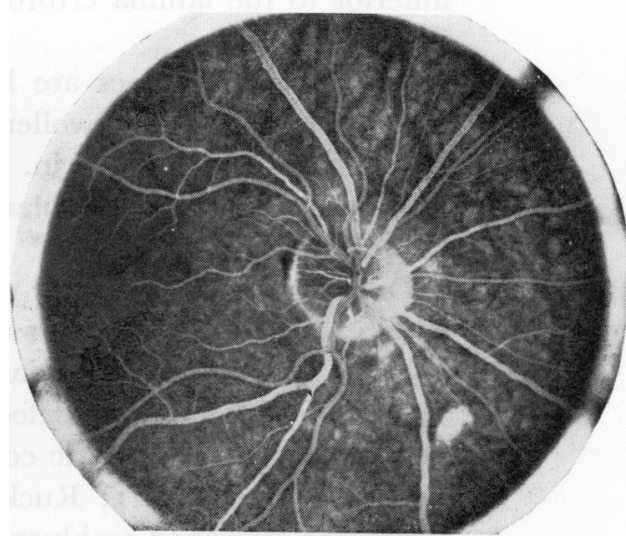

FIG. $2(a)$ Drusen. Fluorescein angiogram, early venous phase, showing no sign of capillary dilatation

FIG. $2(b)$ Drusen. Fluorescein angiogram, late phase, showing irregularity of disc margins and focal concentration of dye with no tendency to spread into the surrounding retina 


\section{Material}

Twenty patients with buried drusen of the optic discs have recently been examined. The majority of them were obtained from the diagnostic index of the Ophthalmic Department in Sheffield, but some had been referred for fluorescein angiography by the Department of Neurosurgery where they were being investigated for suspected papilloedema.

Ocular examination consisted of estimation of visual acuity and refraction; examination of the peripheral and central fields; biomicroscopy and fundus examination with the direct ophthalmoscope; the binocular indirect ophthalmoscope and the fundus contact lens.

Photographic records were taken with the Zeiss fundus camera on Kodachrome II film and stereofluorograms were taken after the injection of $3 \mathrm{ml} .25$ per cent. fluorescein into an antecubital vein. Each patient had a complete general examination with particular attention to the central nervous system.

\section{Results}

In each patient the presence of buried drusen was ultimately confirmed by the characteristic appearance on fluorescein angiography, and stereo-fluorograms proved of considerable value in assessing the degree and localization of disc swelling. Retinal haemorrhages were observed in two patients. Two patients had pseudoxanthoma elasticum, two had retinitis pigmentosa, and one patient had a Bergmeister's papilla on the left disc. No underlying systemic or neurological disease was observed apart from one patient who was mildly hypertensive and one who showed the Stein-Leventhal syndrome.

\section{Case reports}

Haemorrhages were found in the two following patients:

Case 1, a 48-year-old woman, first attended in 1964 with deteriorating vision in the left eye.

\section{Examination}

The corrected visual acuity was then $6 / 9$ and $\mathrm{N} 8$ in the right eye, and $6 / 36$ and $\mathrm{N}$ io in the left. She was found to have pseudoxanthoma elasticum with angioid streaks and early degenerative changes at the left macula. Both discs were considerably swollen because of drusen. There was no venous congestion, no exudate, no hyperaemia, and no vascular anomaly. Extensive retinal and preretinal haemorrhages were present at both posterior poles, in the region of the right macula, and surrounding both discs. The patient was mildly hypertensive.

Diagnosis

The clinical diagnosis of drusen of the discs was confirmed by fluorescein angiography and no further investigations were carried out.

Course

The patient has been reviewed periodically and, apart from some transient fluctuation, her visual acuity has remained fairly static. When she was last seen in December, 1971, there were still extensive retinal and preretinal haemorrhages, the vitreous was clear, and pigmentary changes were evident at both maculae. The angioid streaks and drusen were as previously noted (Fig. 3, overleaf).

Case 2, a 56-year-old woman, presented in October, 1970 , with a 3-week history of dark flickering spots in the corner of the left eye. Her general health was otherwise good and there were no associated symptoms. She was found to have bilateral papilloedema and was referred for Neurosurgical investigation with the following results (Jefferson, 1972).

$\mathrm{C}$ 


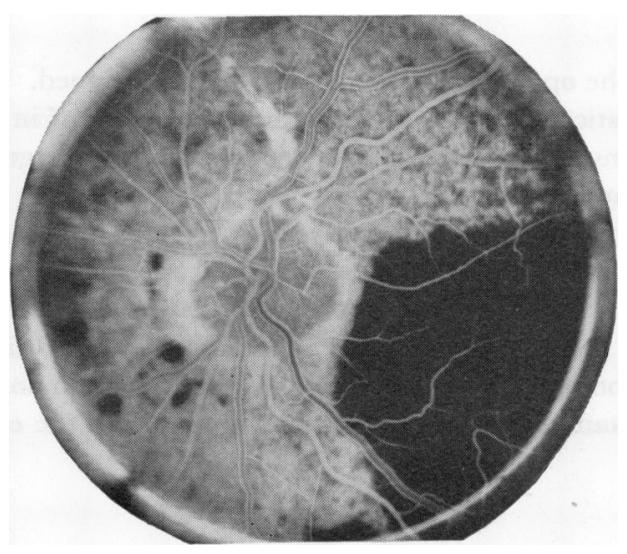

FIG. 3 Fluorescein angiogram, late phase, showing concentration of dye in the drusen. The retinal haemorrhages do not take up fluorescein (Case $\mathrm{I}$, right eye)

\section{Examination}

The Department of Neurosurgery noted that she was obese, had bilateral papilloedema of 2 to 3 dioptres, and enlarged blind spots, but no other G.N.S. abnormality. The visual acuity without correction was $6 / 9, \mathrm{~N} .5$ in the right eye and 6/6, N.6 in the left. Skull and chest $x$ rays, electroencephalogram, echograms, and gamma scan were all normal.

\section{Diagnosis}

Papilloedema without tumour was diagnosed, and the patient was treated with a strict diet, restricted fluids, and diuretics.

\section{Course}

During the next few months she lost a considerable amount of weight but there was virtually no change in the amount of disc swelling. There was, however, a slight reduction in the size of the blind spots. She received further treatment with Sorbitol and then Glycerol with little improvement in the clinical appearance.

In June, I97I, further investigations were carried out. A repeat chest $x$ ray, full blood count. erythrocyte sedimentation rate, serum calcium, phosphate, urea, and electrolytes were all normal. M.S.U. was normal. The levels of lead in the blood suggested recent exposure to high concentrations and this was confirmed by screening the patient's domestic water supply.

She was then referred for fluorescein angiography which revealed buried drusen of the optic discs. On this occasion a splinter haemorrhage was observed on the left disc at 6 o'clock.

She was discharged in November, 1971 , and when the case was subsequently reviewed in January, 1972, the splinter haemorrhage was found to have absorbed (Fig. $4 a, b$, opposite).

\section{Discussion}

The most striking similarities between drusen and true papilloedema are the elevation and enlargement of the disc and the blurring of the disc margins. The significant differences are the absence of hyperaemia, venous congestion, and exudates in drusen, and the fact that the elevation of the disc is mainly confined to the nasal aspect and does not extend beyond the disc margins. A characteristic feature of drusen is the early filling in of the physiological cup (Fig. 5, opposite).

Hoyt and Pont (1962) and Lorentzen (1966) stated that haemorrhages do not occur in association with drusen of the disc and Huber ( 1961 ) maintained that the presence of haemorrhages precluded drusen as a possible diagnosis. 

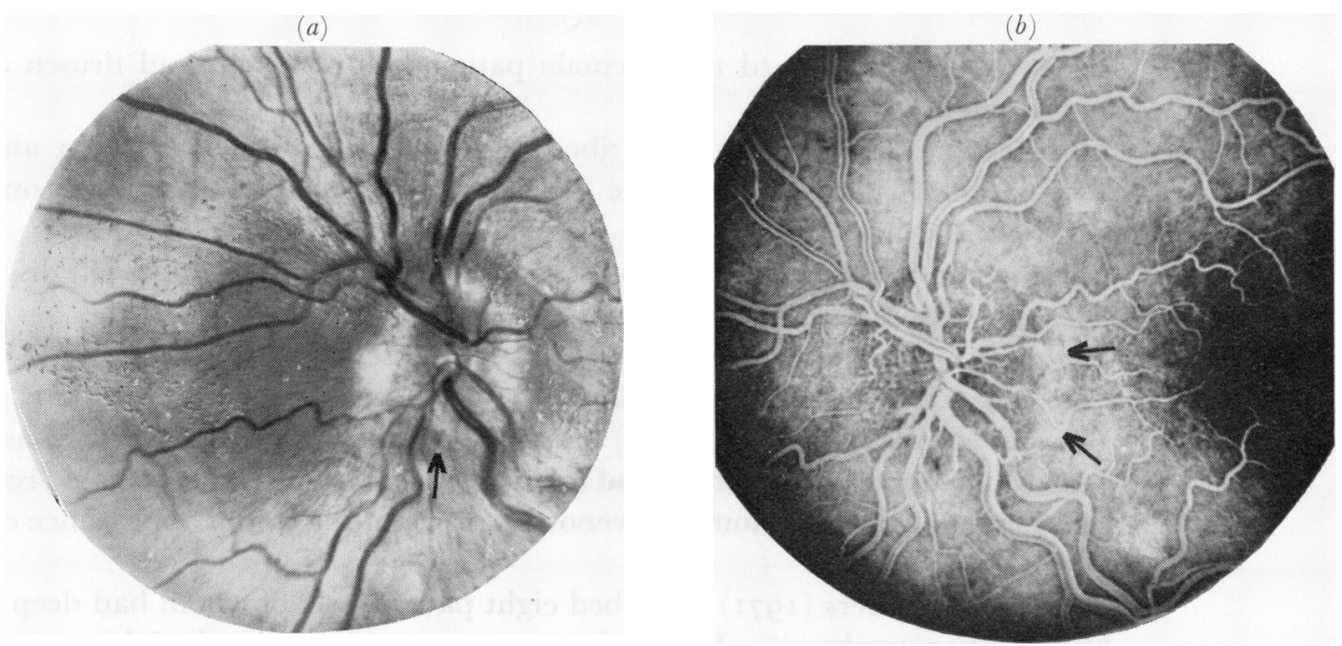

FIG. 4(a) Fundus photograph, showing drusen and a splinter haemorrhage at 6 o'clock (arrowed). The other marks on this picture are artefacts (Case 2, left eye)

FIG. $4(b)$ Fluorescein angiogram, venous phase, showing concentration of dye in drusen (arrowed) and splinter haemorrhage at 6 o'clock (Case 2, left eye)

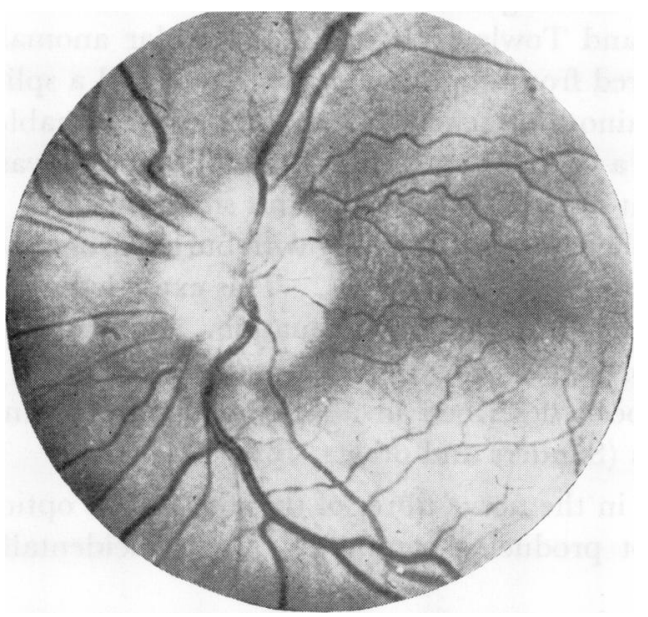

FIG. 5 Drusen. Fundus photograph, showing filling in of physiological cup and characteristic irregular 'scalloped' appearance of disc margins

It must be emphasized, however, that the finding of drusen does not rule out the possibility of an intracranial tumour, and several cases have been recorded in which the visual field defect, because of an underlying intracranial tumour, was mistakenly attributed to the drusen which were also present (Rath, I888; Fejér, I909; Lauber, I91 3, I 92 I ; François, I949; Chambers and Walsh, I95I; Kurus, I956; van Beuningen, I958; Harms, I96o; Rucker and Kearns, I96r ; Steifel and Smith, r96r).

The occurrence of haemorrhages in association with drusen has been described previously. Reese (1940) mentioned a 12-year-old boy with drusen and haemorrhages on the left disc.

Gallais (1952) described an I I-year-old girl with bilateral drusen and a splinter haemorrhage near the left disc which absorbed in three weeks. She had, however, a history of two acute febrile episodes of 2 and 3 weeks' duration separated by an interval of I month just before she attended for investigation, and one cannot discount for certain the relevance of this. 
Brégeat (I956) reviewed three female patients all of whom had drusen and transient haemorrhages.

Gaynes and Towle (1967) described a 19-year-old girl with drusen and a vascular malformation of the left disc. She developed superficial haemorrhages on the left disc after an attack of migraine.

Sanders and ffytche (1967) observed a splinter haemorrhage on the left disc of a 36 -yearold female with drusen and migraine.

In the textbook of Walsh and Hoyt ( 1969), two cases of drusen with splinter haemorrhages on the disc are mentioned in a footnote.

Otradovec and Vladyková (1970) recently described five cases of drusen associated with transient haemorrhages on or around the disc, two of whom had associated retinal vascular anomalies and three of whom had venous stasis resulting in the appearance of a congested disc.

Sanders and others (197I) described eight patients, six of whom had deep peripapillary subretinal haemorrhages. In two instances a massive subretinal haematoma clinically or simulated a choroidal melanoma and, in fact, with this diagnosis in mind, one eye was $ॄ$ enucleated. Three patients had haemorrhages affecting the macular area. One of the 9 patients described had chronic myelocytic leukaemia and the haemorrhages found in this case may well have been due to a bleeding diathesis.

The girl described by Gaynes and Towle (1967) had a vascular anomaly on the left disc and buried drusen, and suffered from migraine. She developed a splinter haemorrhage on the left disc after a migrainous attack and it would seem reasonable to postulate that, in the presence of drusen and a vascular anomaly, the vasodilatation-vasoconstriction sequence of migraine was sufficient to cause bleeding in this situation.

Sanders and others ( 197 I) described a 16 -year-old boy with buried drusen who developed a haemorrhage on the right disc after a game of tennis. This extended into the vitreous, cleared gradually, and twice recurred in the same situation. It would seem that the sudden increase in intravascular pressure was sufficient to cause bleeding.

The haemorrhages that have been described in association with drusen seem to fall into three fairly distinct categories (Sanders and others, I97 I):

(I) Small splinter haemorrhages in the nerve fibres of the disc on the optic head. This is usually a transient feature, not producing symptoms, found incidentally on routine examination.

(2) Haemorrhages of the nerve head extending into the vitreous. This produces a visual disturbance that may well be the presenting symptom. They usually resolve without permanent severe impairment of sight, although some visual defect can persist. (3) Deep peripapillary subretinal haemorrhages. This will obviously cause fairly severe subjective disturbances, especially if the macula becomes involved. Resolution usually occurs with some permanent peripapillary pigment atrophy and residual visual impairment.

These categories no doubt depend upon the site of vessel leakage and the amount and direction of the subsequent haemorrhage. Types I and 2, analogous to the flame-shaped haemorrhages in hypertensive retinopathy occur in the nerve fibre layer, Type 2 extending into the vitreous probably because of a more severe haemorrhage. Type 3 presumably comes deep from the peripapillary network.

In the first patient described above, the haemorrhages have occurred as extensive sheets of retinal and preretinal bleeding which in no way resemble the retinopathy of 
hypertension or the usual clinical appearance of the Grönblad-Strandberg syndrome. The vitreous seems to have remained clear at all times. The interesting feature of this case is that the haemorrhages are far greater both in severity and extent than any so far described; in no previously reported case have such extensive haemorrhages persisted for so long. It is remarkable that the patient still sees $6 / 9, \mathrm{~N}$ io with the right eye.

This case does not fall precisely into any of the three categories described by Sanders and others (197I).

The second patient described above would seem to be a typical example of Type $\mathrm{I}$, both in clinical appearance and in transient duration.

These haemorrhages have two probable explanations:

(I) Progressive enlargement of the drusen in the confined space of the nerve head may gradually lead to back pressure and stasis in the retinal veins even to the extent of producing the appearance of incipient central retinal vein occlusion (Seitz and Kersting, I962; Otradovec and Vladyková, 1970). This progressive obstruction could result in the production of venous malformations and retinal haemorrhages.

It is probable that buried drusen, by causing venous stasis, can produce oedema and congestion of the disc similar in appearance to papilloedema. This period of congestion may, however, regress, and this would explain the apparent slight decrease in the amount of disc swelling which occurred, for example, in Case 2, above.

(2) By virtue of their hard hyaline structure, a mechanical erosion of the adjacent vessels may occur as a result of progressive enlargement.

Although this series is not large enough to estimate the incidence of haemorrhages in association with drusen, it appears from a review of the literature that transient haemorrhages probably occur more frequently than has previously been thought; if a patient is seen for the first time at a stage when haemorrhages are present, especially if there is also some disc oedema due to venous stasis, then the differentiation from early papilloedema could be extremely difficult. In addition, there may rarely be some confusion with choroidal melanoma (Sanders and others, I97I).

In these situations it is suggested that, especially in young persons, the association between buried drusen, venous stasis, and retinal haemorrhages should be borne in mind, and the characteristic field defects and fluorographic appearance of drusen should be sought, to avoid diagnostic confusion and possible unnecessary and unpleasant investigation for the patient.

\section{Summary}

(r) The difficulty in differentiating buried drusen of the disc from papilloedema has been described and details of the clinical features, angiographic appearances, and visual field defects which can assist in diagnosis have been given.

(2) The association between buried drusen, retinal haemorrhages, venous stasis, and vascular anomalies has been emphasized, and two cases with associated haemorrhages have been described.

(3) A brief review of the literature, with particular attention to the association with haemorrhages, has been given.

I wish to express my gratitude to Mr. Ian Strachan for guidance and constructive criticism, Mr. Anthony Jefferson for the clinical details of Case 2, for access to his patients, and for his co-operation in discussing his cases. I should also like to thank the consultant ophthalmologists for permission to examine their patients, Mrs M. Sayner of the Department of Medical Photography, and Miss Vanessa Clark for secretarial assistance. 


\section{References}

Beuningen, E. van (1958) Klin. Mbl. Augenheilk., 133, 585

BRÉGEAT, P. (1956) 'L'oedème papillaire", p. 244. Masson, Paris

Chambers, J. W., and WAlsh, F. B. (195 I) Brain, 74, 95

cIBIS, P. (1940) Klin. Mbl. Augenheilk., 105, 78

ERNEST, J. T., and KRILl, A. E. (1966) Amer. F. Ophthal., 62, I

FEJÉR, J. (1909) v. Graefes Arch. Ophthal., 72, 454

FRANÇOIS, P. (1949) Ann. Oculist. (Paris), 182, 249

GALlAIS, P. (1952) Rev. Oto-neuro-ophtal., 24, 369

Gaynes, P. M., and towle, P. A. (1967) Amer. F. Ophthal., 63, I693

GIFFORD, H. (1895) Arch. Ophthal. (N.Y.), 24, 395

haRms, H. (1960) Klin. Mbl. Augenheilk., 136, 122

hoYt, w. ғ., and pont, м. Е. (1962) 7. Amer. med. Ass., 181, 191

hUber, A. (1961) "Eye Symptoms in Brain Tumors", p. 129. Mosby, St. Louis

Jefrerson, A. (1972) Personal communication

KURUS, E. (1956) Ber. dtsch. ophthal. Ges., 1955, 59, 46

LANSGhe, R. K., and RUCKer, c. w. (1957) A. M. A. Arch. Ophthal., 58, I I 5

LAUBER, H. (1913) Z. Augenheilk., 29, 201

(192 I) v. Graefes Arch. Ophthal., 105, 567

LIEBreich, R. (1868) Klin. Mbl. Augenheilk., 6, 426

LORENTZEN, S. E. (1966) Acta ophthal. (Kbh.), Suppl. 90

McPherson, S. D. (1955) Amer. F. Ophthal., 39, 294

MILLER, S. J. H., SANDERS, M. D., and FFYTCHE, T. J. (1965) Lancet, 2, 65 I

MORAX, P. v. (1963) Arch. Ophtal. (Paris), n.s. 23, 476

MÜLLER, H. (1858) v. Graefes Arch. Ophthal., 4, abt 2, p. I

Otradovec, J., and vladyková, J. (1970) Sborn. lék., 72, 206

POLliot, P., and lods (1963) Arch. Ophtal. (Paris), 23, 476

RATH, w. (I888) v. Graefes Arch. Ophthal., 34, abt 4, p. 8i

REESE, A. B. (1940) Arch. Ophthal. (Chicago), 24, 187

Rosen, E. S. (1969) "Fluorescence Photography of the Eye", p. 23. Butterworth, London

RUCKer, c. w. (1944) Arch. Ophthal. (Chicago), 32, 56

$\longrightarrow$, and keARNs, T. P. (196I) Amer. F. Ophthal., 51, I 5

SANDERS, M. D., and FFYTCHE, T. J. (1967) Trans. ophthal. Soc. U.K., 87, 457

SANDERS, T. E., GAY, A. J., and NEWman, J. (1971) Amer. F. Ophthal., 71, 204

SEItz, R., and kersting, G. (1962) Klin. Mbl. Augenheilk., 140, 75

STIEFEL, J. W., and SMith, J. LAWTON (196I) Arch. Ophthal. (Chicago), 65, 8I 4

THOMSON (1898) Post-Graduate (N.Y.), 14, 954

WALSH, F. B., and ноYт, W. F. (1969) “Clinical Neuro-Ophthalmology", 3rd ed., vol. I, p. 673.

Williams and Wilkins, Baltimore 